\title{
SISTEMAS DE CAPTACIÓN Y DISTRIBUCIÓN DE AGUA DE PROBABLE ORIGEN ÁRABE, EN ALBATERA Y CREVILLENTE
}

Por

MANUEL DE GEA CALATAYUD

Nuestro estudio es el resultado de una serie de prospecciones arqueológicas en torno a las sierras de Albatera y Crevillente, realizadas en 1987 por encargo de la Unidad Técnica de Arqueologia (Consellería de Cultura), con la finalidad de inventariar los yacimientos arqueológicos de la Comarca del Bajo Segura, que nos permitieron detectar las huellas de una serie de sistemas y técnicas hidráulicas de tradición antigua ideadas o adoptadas, principalmente, para crear espacios irrigados, abastecer a los núcleos de población y atender las necesidades de los ganados.

El sureste de la Península Ibérica en su lucha contra la sequía ofrece todo un muestrario de esta tecnología (1). Las sierras de Albatera y Crevillente pertenecen a las dos terceras partes de este territorio clasificadas como áridas o semiáridas, es decir, bajo el limite de los $400 \mathrm{~mm}$. de precipitaciones anuales (que acusan notables irregularidades de unos años a otros y suelen caer en breves y violentos chaparrones), y el isotermo de $16 .^{\circ}$.

(1) Destacamos los estudios dedicados a la irrigación por aguas de avenidas de VILA VALENTI, J.: «L'irrigation par nappes pluviaies dans le Sud-Est de l'Espagne», Mediterranée, 2, p. 19-32, y "La lucha contra la sequia en el sureste de España», ESTUDIOS GEOGRAFICOS, XXII, 82, p. 25-48; de MORALES GIL, A.: «El riego con agua de avenidas en las laderas Sub-áridas;, papeles del Departamento de Geografia de la Universidad de Murcia, 1, p. 167-183; de MORALES, A. y BOX AMORÓS, M.: «El aprovechamiento del agua y de los suelos en un dominio semiárido: la Cuenca del Barranco Blanco. Agost (Alicante) s, Investigaciones Geográficas 4, Alicante, 1986, p. 7-24; el sugerente trabajo de BERTRAND, M. y CRESSIER, P.: «Antiguos sistemas de irrigación en el valle del Andarax (Almeria)», Actas del I Congreso de Arqueología Medieval, Huesca, 1985; y para las Balerares, el fundamental trabajo conjunto de BARCELO, M., CARBONERO, M.A., MARTi, R. y ROSELLÓ-BORDOY, G.: «Les aigües cercades. (Els qanat(s) de l'illa de Mallorca)», Instituts d'Estudis Baleárics, 1986. 


\section{Descripción de las estructuras hidráulicas}

El área geográfica objeto de nuestro estudio está formada por un amplio glacis disecado y en parte acarcavado, extendido al pie de las sierras de Albatera y Crevillente. Esta zona ofrece un relieve labrado por ramblas de diversa categoría que descienden culebreando hasta morir en el llano (Rambla de La Algüeda, Barranco de San Cayetano y Barranco de la Rambla de Crevillente). Son unas tierras excelentes, con buena exposición y sin riesgo de heladas, que facilitan la presencia y el abastecimiento de acuiferos superficiales, y ofrecen una clara muestra de estas estructuras.

\section{A) LAS TÉCNICAS DIRIGIDAS AL APROVECHAMIENTO DE LOS RECURSOS HIDRÁULICOS SUPERFICIALES}

- Técnicas de inundación dirigida o riego de boqueras:

- Los «caminos de agua", trazados entre las terrazas de cultivo que captan el agua directamente de las ramblas afluentes, aprovechando sus avenidas estacionales (2).

- Los túneles de desagüe. Un ejemplo de este sistema - hoy en día en desuso y en gran parte colmatado- se puede encontrar en la Rambla de San Cayetano (Finca «La Molineta»). Esta técnica hidráulica deriva las aguas de avenida del lecho de la rambla, aprovechando la curva de uno de sus meandros, desde donde se enlaza mediante un túnel subterráneo que salva un obstáculo natural, con las parcelas próximas a su cauce, ordenadas en terrazas (Fig. 1).

Sobre el conducto subterráneo hay que añadir que está excavado sobre formaciones detríticas muy impermeables y de difícil erosión, por lo que sus paredes no requieren recubriciones de piedra y mortero.

Por el uso estacional de estas dos técnicas, generalmente, van asociadas a otras capaces de producir un flujo de agua perenne que permita mantener una explotación de cultivos de regadío.

- Los manantiales superficiales regulados por albercas. Un ejemplo de este aprovechamiento lo hallamos en el despoblado de la Finca «Las Parretas» (Rambla de San Cayetano), asociada a un «camino de agua». En este caso, al estar el nacimiento de agua en la superficie por encima de la cañada irrigada, el agua es regulada directamente por una alberca de forma circular, que irriga en la actualidad una superficie de 15 tahullas, preparada en terrazas (Fig. 2).

\section{B) LA CAPTACIÓN DE AGUA MEDIANTE POZOS ARTESIANOS}

Un nuevo sistema hidráulico se abre, de igual manera que los anteriores, en el lecho de la rambla, pero ahora para abastecerse mediante pozos artesianos de la corriente subálvea fluvial.

Por regla general, este sistema procede a la búsqueda del agua mediante profundos pozos de planta cuadrada, construidos de sillarejo, que perforan la superficie

(2) M. BERTRAND y P. CRESSIER señalan la existencia de técnicas similares en Mallorca y en Marruecos, op. cit., p. 570 . 
hasta que la corriente subálvea encuentra salida y sube naturalmente. Seguidamente, este flujo es canalizado por un conducto de reducidas dimensiones $-20 \times 10 \mathrm{~cm}$. y sección semicircular en la Finca «La Palaya»- construido en obra de cal y cubierto de hormigón hidráulico. Esta canalización, siguiendo una suave pendiente, conduce el agua hasta hacerla desembocar en una alberca (Fig. 3).

La longitud de estas canalizaciones depende del tramo que tengan que sortear, desde que recogen el agua de los pozos hasta la cañada a irrigar, donde se ubica la alberca.

Hemos constatado este sistema en dos zonas diferentes de la Rambla de San Cayetano (Crevillente):

El sistema de la Finca "La Palaya», aún en funcionamiento aunque con cambios notables - sustitución de la antigua canalización por un tubo de uralita y reconstrucción del pozo con ladrillos y cemento-, nos ha permitido entender su función. Este sistema abastecia con un flujo perenne de agua (mayor en la época de lluvias) a una aiberca con una capacidad de 500.000 I., llamada «La Colorá» por estar pintada de almagra al interior y exterior.

El sistema de la Finca "La Molineta» abandonado e invadido por la vegetación, sin embargo, nos ha permitido observar cómo se construian los antiguos pozos, a base de sillarejo recogido con barro y planta cuadrada (Fig. 4). En esta finca asistimos a la asociación de este sistema con un túnel de desagüe.

Las albercas están construidas de hormigón hidráulico muy resistente, con enfoscado interior.

\section{C) LAS GALERIAS DE CAPTACIÓN DE AGUA POR DRENAJE O QANATS}

Con respecto a este sistema hidráulico, de concepción más sofisticada, e introducido a gran escala en occidente por los árabes (3), nuestra atención se ha dirigido primordialmente a estudiar en profundidad el Qanat de La Algüeda (Albatera), que damos a conocer en esta publicación. Más adelante también destacaremos el pape! fundamental que representaba el monumental Qanat de Crevillente, citado desde antiguo.

El Qanat de La Algüeda es una extensa galería subterránea de captación de agua por drenaje de esta (4). Su funcionalidad era conducir el agua a la superficie, hasta hacerla desaguar en una alberca que regulaba la irrigación de un gran barranco aterrazado (Fig. 5, 6).

Este qanat estaba constituido por una serie de elementos estructurales bien definidos:

(3) Sobre invención y difusión de esta técnica hidráulica, véase el estudio de GOBLOT, H.: «Les qanats. Une technique d'acquisition de L'eau», Paris, 1979. También el apartado que dedica GLICK, T.F., al qanat en su innovadora obra: «Regadio y Sociedad en la Valencia Medieval», Valencia, 1988.

(4) Respecto a esta definición propuesta por H. GOBLOT, op. cit., p. 25; M. BARCELÓ y M.A. CARBONERO desarrollan una serie de matizaciones puntuales sobre otras formas de construcción de las galerias de drenaje, que no sean necesariamente siguiendo una técnica minera, suberráneamente. Trasladando la cuestión principal que estructura esta técnica hidráulica, a la modificación artificial de la pendiente a través de la cual se conduce el agua a la superficie, según el planteamiento general que hace J.C. Wilkinson, op. cit., p. 39. 
$\left.1 .^{\circ}\right)$ La galería o mina, que presenta una forma diferente según los distintos tramos:

- Un tramo inicial, excavado en la roca de trazado muy irregular, que debia comenzar a partir del pozo madre (el cual nos ha sido imposibie alcanzar por estar colmatada la zona de su ubicación). Este tramo se bifurcaba más adelante en otra galería de recogida marginal de aguas, excavada igualmente en la roca, que buscaba aumentar el volumen de agua captada (también en parte colmatada) (Fig. 7).

- Un tramo intermedio, caracterizado por su estrechamiento. Configurado a partir de que las paredes del tramo excavado, ahora en su mayor parte de tierra, se refuerzan utilizando, de forma muy cuidada, la técnica de encastar piedra en obra de mortero, formando asi una galería interior enlucida que culmina en un arco de forma triangular o de medio punto, este último realizado a partir del soporte de una cimbra de madera (Figs. 8, 9 y 10).

-Y, finalmente, el tramo más largo, de unos 300 metros de longitud, que llega a la superficie. Esta galería es de sección ligeramente peraltada y está construida a partir del reforzamiento de las paredes de tierra del tramo excavado, hasta una altura de 1 '75 m., con piedra encastada en obra de mortero, cubierta ahora con un arco rebajado realizado a partir del soporte de una cimbra de cañizo o madera, que ha dejado su impronta. Este tramo de galería, sólo nos ha sido posible seguirlo en un trayecto de $40 \mathrm{~m}$. por haber sido cegado desde la superficie rellenando con tierra todos los pozos de aireación (Figs. $11,12,13,14,15)$.

La técnica de construcción empleada, al menos en este tramo de qanat, es la de la excavación a cielo abierto (a diferencia de la excavación subterránea del primer tramo) que una vez organizado el sistema de cobertura de la galería se cubría con tierra. El empleo de esta técnica hace posible la utilización de cimbras para realizar la cubierta, permitiendo además la construcción de pozos de ventilación de 0’40 m. de diámetro, insuficientes para que una persona puede pasar.

La galería de el Qanat de La Algüeda en su totalidad, mide más de 350 m.; en línea recta, presenta una desnivelación de $50 \mathrm{~m}$. entre su tramo inicial y final. Su altura es muy variable 1'75 y 1'30 m. Cada cierto tramo la galería presenta lo que cabe interpretar como unos reforzamientos de la cubierta, realizados de mampostería recogida con mortero.

$2^{\circ}{ }^{\circ}$ L Los pozos de ventilación, que se abren a intervalos de 5 a $15 \mathrm{~m}$., conectándose con la galería subterránea. Presentan planta circular, entre 0'40 y 0'90 m. de diámetro; y servian, primero, para facilitar el trabajo de construcción del conducto subterráneo, y una vez en funcionamiento, como ventilación y puntos de entrada para los trabajadores de mantenimiento. Sus medidas varían según la topografía de la zona que perforan, presentando mayor altitud en el tramo inicial (Fig. 16).

3. $\left.{ }^{\circ}\right)$ El conducto de eliminación de los excedentes de agua, en este caso, se dispone subterráneamente paralelo al lecho de la rambla - de aquí que lo haya alcanzado la erosión-, permitiendo el desagüe, en época de grandes lluvias, de los excesos de agua acumulados hasta hacerlos desembocar en la rambla. 
$4^{\circ}{ }^{\circ}$ El sistema de conducción a cielo abierto o canal al aire libre, último tramo del qanat que transportaba el agua a la alberca. De esta canalización sólo se conserva su caño final de piedra conectado a la alberca, desde el que se vertía un caudal de abastecimiento medio de $1 / 2$ litro por segundo.

$\left.5^{\circ}{ }^{\circ}\right)$ La alberca de planta circular, eje regulador del sistema. Con una capacidad de cerca de 500.000 litros (Fig. 17). Desde la cual se irrigaba una superficie de terrazas abancaladas de aproximadamente $45.180 \mathrm{~m}^{2}$ (unas 42 tahullas), que se disponían en forma de abanico siguiendo el declive del barranco hasta ser cortadas por la afilada Sierra del Cuchillo (Fig. 18).

La captación del Qanat de La Algüeda se localiza próxima al lecho de uno de ios afluentes secundarios de la rambla del mismo nombre. Es por esto, por lo que para preservarlo de la fuerza de las aguas de avenida, su tramo cercano al lecho se refuerza con estructuras protectoras. Primero la galeria en este punto atraviesa el torrente oblicuamente con el fin de ofrecer mayor resistencia con su punto más débil (5). Segundo las paredes de la galería se engrosan más de $1 \mathrm{~m}$. Y finalmente, la bóveda de cubrición, que en un pequeño tramo daba al exterior, se prepara con una rampa enlucida para deslizar mejor el agua de la escorrentía.

El qanat a causa de su larga etapa en funcionamiento, ha sido objeto de reparaciones modernas, realizadas, por lo general, con mampostería recogida con yeso, que afectan, sobre todo, al reforzamiento de las paredes de la galería y los pozos de ventilación.

Con respecto al significado toponímico de la Finca «La Algüeda» (que da nombre por extensión a toda la rambla) no aparece en los principales estudios realizados hasta ahora (6). La aparente estructura árabe del topónimo sería un indicio más para fechar su utilización en aquella época (siglos VIII-XIII), sin descartar un uso anterior y posterior.

Este costoso y complejo sistema hidráulico, cuidadosamente planificado y construido, con toda probabilidad, por profesionales musulmanes (7) -ya observaremos además su similitud constructiva con el Qanat de Crevillente, señalado por las fuentes como de implantación musulmana-, estuvo en funcionamiento hasta 1964, manteniendo el «Oasis» de La Algüeda con toda clase de frutales, legumbres, hortalizas y cítricos. Guarnecido, además, por un microclima que no sufre heladas, a diferencia de las tierras situadas más altas y más bajas de la sierra.

(5) Esta misma caracteristica morfológica es señalada por M. BARCELÓ y M.A. CARBONERO para la mayor parte de los ganats que atraviesan torrentes en la isla de Mallorca en uTopografia i Topologia dels qanat(s) de l'illa de Mallorca”, Actas del I Congreso de Arqueología Medieval Española, Huesca, 1985.

(6) Véase TERÉS, E.: Materiales para el estudio de la toponímia Hispanoárabe. Nómina fluvial, Madrid, 1986, donde estudia exhaustivamente los derivados de wäd «rio», aparentemente semejante a nuestro Algüeda. Nada tampoco en M. ASíN PALACIOS: Contribución a la toponimia árabe de España, Madrid-Granada, 1944; E. MOREU-REY: Els nostres noms de lloc, Mallorca, 1983; C. BARCELÓ TORRES: Toponimia arábica de Pais Valencià. Alqueries y castells, Xàtiva, 1922.

(7) Al respecto de la presencia de constructores profesionales de qanats en Al-Andalus, es probable que Abo Allah ibn Yunus al-Muhandis («el ingeniero»), que construyó el complejo sistema de ganats de Marrakesh durante el reinado de Ali ibn Yusuf ib Tashufin (1107-†143), fuera de origen andalusi. Véase OLIVER ASÍN, J.: Historia del nombre "Madrid", Madrid, CSIC, 1959, p. 137-140. 


\section{Importancia de los aprovechamientos hidráulicos: el caso de Crevillente}

Hay que resaltar la importancia de estos sistemas hidráulicos tradicionales, en la organización de la población de estos ámbitos semiáridos de montaña.

Un claro ejemplo de lo que decimos, es el municipio de Crevillente, situado al pie de la sierra que lleva su nombre. El cual ofrece una hidráulica rural clara, perfectamente adaptada a las condiciones naturales.

En esta, la posición de los principales manantiales surgidos a alturas medias organizan la distribución del hábitat: por encima de estos es escaso y aislado, aprovechando fuentes secundarias a través de las técnicas hidráulicas que hemos mencionado (pozo-alberca y pequeños qanats), o en su caso, aprovechando la escarrentía cíclica de la rambla (túneles de desagüe y caminos de agua); los cuales irrigan cañadas inconexas topográficamente, organizadas en terrazas o bancales. Por debajo de estas fuentes principales el hábitat se va densificando y se organiza según los ejes de distribución del agua, conducida a partir de un complejo y monumental sistema hidráulico: un largo qanat que descendía por el mismo lecho de la rambla de Crevillente bifurcándose en acequias (sequías), las cuales irrigaban cañadas, accionaban molinos y, finalmente, abastecían de agua a la población principal, situada en la ladera al pie de la montaña (Fig. 20).

Sabemos por la documentación medieval que la única agua disponible por el municipio de Crevillente era la procedente de la Fuente Antigua, situada a 3' $5 \mathrm{~km}$. al N.O. del pueblo, que era conducida, en principio, por una mina o qanat, hasta llegar al interior de la población a través de una sequía (Fig. 21).

Las primeras citas que tenemos de este sistema las recogemos de María Teresa Ferrer i Mallol (8):

«Una de 3 de febrer de 1321 , en la confirmació reial de la concessió a Llorenç Fri-
tós, jurisperit d'Oriola, d'un saltant d'aigua a la sèquia de Crevillent, al costat de la
muntanya, en el lloc dit Zahara, per a construir-hi un molí; una altra del 10 de setem-
bre de 1361 , en un manament de la reina al procurador d'Elx i Crevillent perqué
fes reconstruir els molins destruïts pels castellans durant la guerra, ja que només
n'hi havia un, el que ell havia fet prop de la porta de l' Adarop", que havia de deixar
de moldre quan els moros regaven les terres, perquè treballava amb la mateixa aigua,
i no era suficient, per la qual cosa els moros havien d'anar a moidre a Elx. La darrera
citació, del primer de febrer de 1385 , es troba en una donació feta per l'infant Martí
a Muhammad Abeaquel, iloctinent de l'alcaldi de Crevillent, de dues tafulles i mitja
de terra situades a tocar de la porta del lloc, dita "Adarop", i limitant per la part infe-
rior amb la sèquia i per la part superior amb un carrer".

En estas citas podemos observar, además, las graves dificultades y la tarea de reconstrucción que tuvo que soportar Crevillente para sobrevivir, tras la conquista cristiana y la guerra entre Castilla y Aragón. Con este fin se vuelve a rehacer el sistema hidráulico, alterando, en algunos casos, el frágil equilibrio colectivo de la aljama sarracena de Crevillente.

Estos textos deben completarse con otro muy posterior que muestra la continuidad del sistema. Son las observaciones de Cavanilles en el siglo XIX acerca de lo

(8) Les aljames sarraïnes de la Governació D'Oriola en el segle XIV, Barcelona, 1988, p. 93. 
que representaba esta hidráulica rural (9):

«Estas huertas, en cantidad de 100 tahullas, forman graderías, y se riegan con las aguas que nacen en los montes, cuyas entrañas creen los naturales ricas en depósitos ó rios considerables; $y$ viendo las ventajas que produce el riego, quisieran extenderle á todo el término. Con este fin han taladrado montes, excavado canales subterráneos, y siguen sus ideas hasta encontrar manantiales. Muchos que parecen copiosos al descubrirse, se empobrecen muy pronto, huyendo al parecer las aguas para fatigar la constancia de aquellos hombres, que redoblando sus esfuerzos las persiguen hasta asegurarles. Así lo han hecho en varias partes del término, especialmente en la fuente principal, cuyos depósitos están ocultos en las entrañas del monte á 52 varas de su superficie, y á media legua de la villa. En este largo trecho están las costosas obras que hacen tanto honor á los de Crevillént. Desde la población empieza un canal sólido de mampostería que sigue media hora hasta encontrar la boca de la mina, atravesando ántes un barranco sobre un grande arco; la mina se prolonga por lo interior del monte 5984 palmos hasta el depósito natural del agua dulce; y á los 5128 se ve la confluencia de otro canal de 392 palmos que conduce á un segundo depósito ménos abundante».

«Es muy laudable el zelo é industria de los que buscan fondos para emprender y perfeccionar obras tan útiles; pero mas laudables son aquellos que sin fondos las conciben y executan á expensas propias, como han hecho los de Crevillént. Miguel Francia de Guillém notó juncares y humedad en los barrancos distantes una legua al sudeste de la villa; vió vestigios de los encañados y excavaciones de los Moros en la fuente Marchante, y creyó posible descubrir aguas para regar algunas cañadas: comenzó sus trabajos, y consiguió hallar una corta porción, que conduxo desde el manantial á una balsa de 14 palmos de profundidad por un canal sólido de 240 varas, donde las acopió, para guiarlas despues por otro canal de 150 varas á los campos de riego. Animados con el exemplo de Guillém otros vecinos, aunque con ménos caudales, intentarón registrar las entrañas del monte, donde al parecer se ocultaban las aguas que burláron los trabajos porfiados de los Moros, y últimamente los de Guillém: hiciéron excavaciones profundas y una mina hasta dar con un manantial tan copioso, que excedia á la fuente principal. Fué indecible el gozo que produxo este hallazgo, pero duró solamente 37 dias, quedando al fin de ellos tan pocas aguas, que se necesitaban siete dias para llenar la balsa de Guillém, que este jamas habia podido llenar en ménos de un mes. Parece que la suerte que cupo antiguamente á los Moriscos, y en nuestros dias á Guillém y á sus sucesores, debia entibiar el ardor y deseos de hacer nuevas tentativas y descubrimientos; pero vemos lo contrario en Crevillént, cuyos vecinos porfian siempre y siguen sus ideas. En efecto, han emprendido otra mina, de la que tienen 1191 paimos, con nueve pozos ó respiraderos de 76 á 120 palmos de profundidad, y solamente les faltan 200 para llegar al manantial ó rio que ellos dicen; donde á la profundidad de 120 palmos apénas agujereáron la peña saltáron las aguas con tal fuerza, que subiéron y permanecen á 14 palmos de altura. Esperan ver muy presto coronadas sus fatigas, y bien recompensados sus sacrificios, prometiéndose aguas copiosas y permanentes para aumentar el riego y los frutos».

Las citas son extensas, pero merecen la pena detenerse en ellas: por una parte, se nos muestra lo que representan estos aprovechamientos, en virtud de la impor-

(9) CAVANILLES inspeccionó personalmente el sistema de Crevillente describiéndolo detalladamente en sus «Observaciones sobre la historia natural, geografla, agricultura, población y frutos del Reyno de Valencia», II, Zaragoza, CSIC, 1988, p. 274-279. En la actualidad es posible seguir el sistema hidráulico en algunos tramos, aunque, si no se toman prontas medidas para su consolidación, continuarán desprendiéndose de los bordes del lecho de la rambla nuevos tramos de galería, con auténtico peligro en el tramo que coincide la travesía a la sierra con la rambla. 
tancia que tienen para la población, la organización del poblamiento y la transformación del ecosistema; y por otra, se nos advierte de como estos aprovechamientos se guian, casi siempre, por antiguos sistemas implantados y organizados socialmente «por los moros».

\section{Origen y problemas de datación}

Es difícil precisar la datación de estos sistemas hidráulicos con argumentos propiamente arqueológicos:

- El registro arqueológico superficial de los emplazamientos de hábitat plantea numerosos problemas derivados de las remodelaciones, desmontes y la potente erosión debida a las aguas torrenciales. Estas circunstancias provocan que, en la mayoría de los casos, se hallen las cerámicas de la última etapa de explotación.

- De igual manera, la anegación de los túneles de desagüe, y la fuerte erosión del lecho de la rambla que los deja a varios metros por encima de su nivel actual, nos permite únicamente entrever su antigüedad, dado que el avance de esta erosión depende tanto de la resistencia que ofrece el terreno como de la potencia y frecuencia de las avenidas.

- El sistema constructivo, tanto de pozos como de albercas y galerías, emplea técnicas utilizadas en época islámica, aunque hay que decir que estas técnicas, todavía son utilizadas en época gótica:

-Piedra encastada en obra de mortero: galerías de los qanats de La Algüeda y Crevillente.

- Cubiertas realizadas a partir de cimbras de cañizo: Qanat de La Algüeda. Un claro ejemplo de este tipo de cubrición lo podemos observar en la prisión del s. XII conservada en el Castillo de Guadalest.

-Empleo de capas protectoras de pintura almagra en los enlucidos de mortero: alberca «La Colorá» (Finca «La Palaya«) y Qanat de Crevillente. Este último además presenta muestras decorativas muy representativas del mundo islámico (10).

Sin embargo, todo nos lleva a pensar - los datos técnicos y morfológicos se acoplan perfectamente con los históricos- en una implantación árabe-bereber.

Es de sobra conocida, por una parte, la escasa incidencia del poblamiento romano de la zona; estando aún latente la importancia del poblamiento andalusí, acentuada por el amplio período cronológico que tiene este asentamiento en Crevillente y Albatera, aún después de la conquista cristiana.

A este respecto son significativas las citas de los geógrafos y literatos árabes:

- Al-Himyari, en el siglo XII, sitúa la ciudad (Madina) de Orihuela; a 12 millas de Murcia, 40 de Cartagena y 20 de Crevillente (Qarbalyan). De esta última

(10) ROSElló BORDOY, G.: op. cit., p. 51. 
población Al-Himyari, además de su cercanía y estrecha relación con Orihuela, menciona también cómo sus tierras están bien regadas, destacando, a la vez, sus numerosos olivares (11).

- Ibn Al-Abbar, un siglo después, vuelve a citar, como demarcación menor dependiente de la capital regional murciana, a un Al-Qirbilyani o de Qirbilian (12).

Posteriormente, dentro ya de la etapa de ocupación y conquista del Reino de Murcia por Castilla y Aragón, destaca de forma singular la existencia de un señorío musulmán, autónomo e independiente, gobernado por el Ra'is de Crevillente Ahmad Abu Dja'far, y poco tiempo después por su heredero y sucesor en el cargo Muhammad Ibn Hudayr (13), el cual es confirmado por Jaime II como «Justicia de todos los Sarracenos del reino de Murcia, desde Orihuela, Guardamar y Alicante hasta Beniopa (junto a Gandía)» (14).

Este poblamiento con impronta musulmana se perpetúa durante bastante tiempo. Una buena muestra de la larga pervivencia y el absoluto predominio de estas comunidades moriscas en torno a la zona que estudiamos, es la cita de 1579, extraída del memorial dirigido por la ciudad de Orihuela a Felipe II, contradiciendo las pretensiones de Callosa de segregarse de su jurisdicción (15):

"Otrosi, que el dicho lugar se Callosa y otras aldeas de la dicha ciudad están situadas un quarto de legua, media legua, una legua y lo más largo quatro leguas de muchos lugares de moriscos, como son Redován, Coix, la Granja, Albatera, Crevillente, Azpe, Novelda y Elda con su valle y Avanilla, los cuales estan muy poblados de dichos moriscos».

Finalmente, observemos un dato de carácter demográfico digno de tenerse en cuenta. En 1609, año de la expulsión de los moriscos, Crevillente contaba con unas 400 familias descendiendo a raíz de la expulsión a 194 —unos 870 habitantes- (16).

En conclusión, los datos puntuales recogidos anteriormente de orden arqueológico, toponímico y documental, permiten deducir, como hipótesis de trabajo, que el despliegue original de esta tecnología y el papel decisivo que ha tenido en la modificación del ecosistema de las sierras de Albatera y Crevillente se iniciará a partir de la ocupación islámica medieval de la zona, que va a determinar, en este ámbito montañoso, unas formas de vida material acorde con lo que se conoce de la organización y de las estructuras de las comunidades rurales del mundo islámico medieval (17).

(11) GARCIA ANTÓN, J.: «Las ciudades de Alicante durante el Islam», Historia de la Provincia de Alicante, III, 1985.

(12) EPALZA, M.: «L'Ordenacio del territori del País Valencià abans de la Conquesta, segons lbn-Al-Abbar», Sharc Al-Andalus 5, 1988, p. 52.

(13) GUICHARD, P.: «Un señor musulmán en la España cristiana»: el Ra'is de Crevillente (1243-1318)», Alicante, 1976.

(14) ESTAL, J.M. del: «Vasallaje del señorio musulman de Crevillente a Jaime II de Aragón», Sharc Al-Andalus 3, 1985, p. 87

(15) VILAR, J.B.: "Callosa de Segura (Alicante) en la coyuntura de 1579".

(16) ROSELLÓ VERGER, V.M. a: Geografia de la Provincia de Alicante, 1978, p. 577.

(17) Respecto a las constantes que definen la organización de estas comunidades en estos ámbitos. Véase $M$. BERTRAND y P. CRESSIER: op. cit., p. 578. 


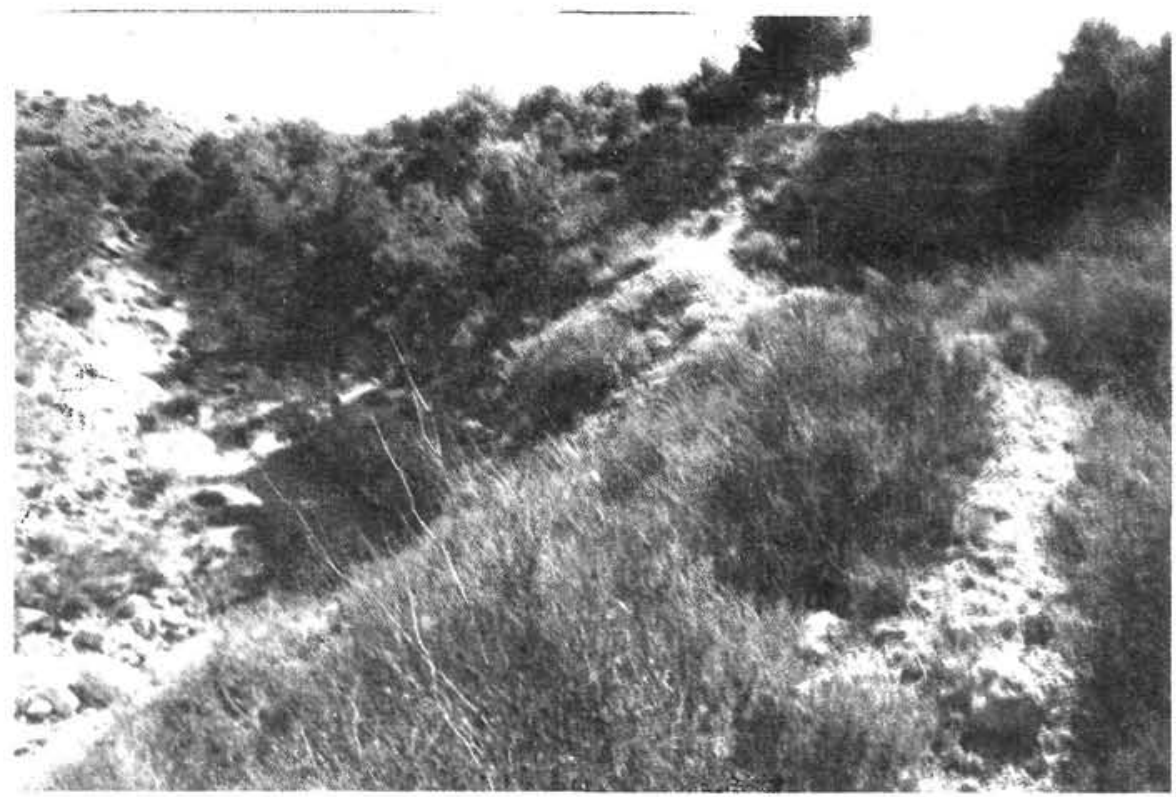

FIG. 1.-Túnel de desagüe en gran parte anegado por la fuerte corrosión de la Rambla de San Cayetano (Finca "La Molineta»).

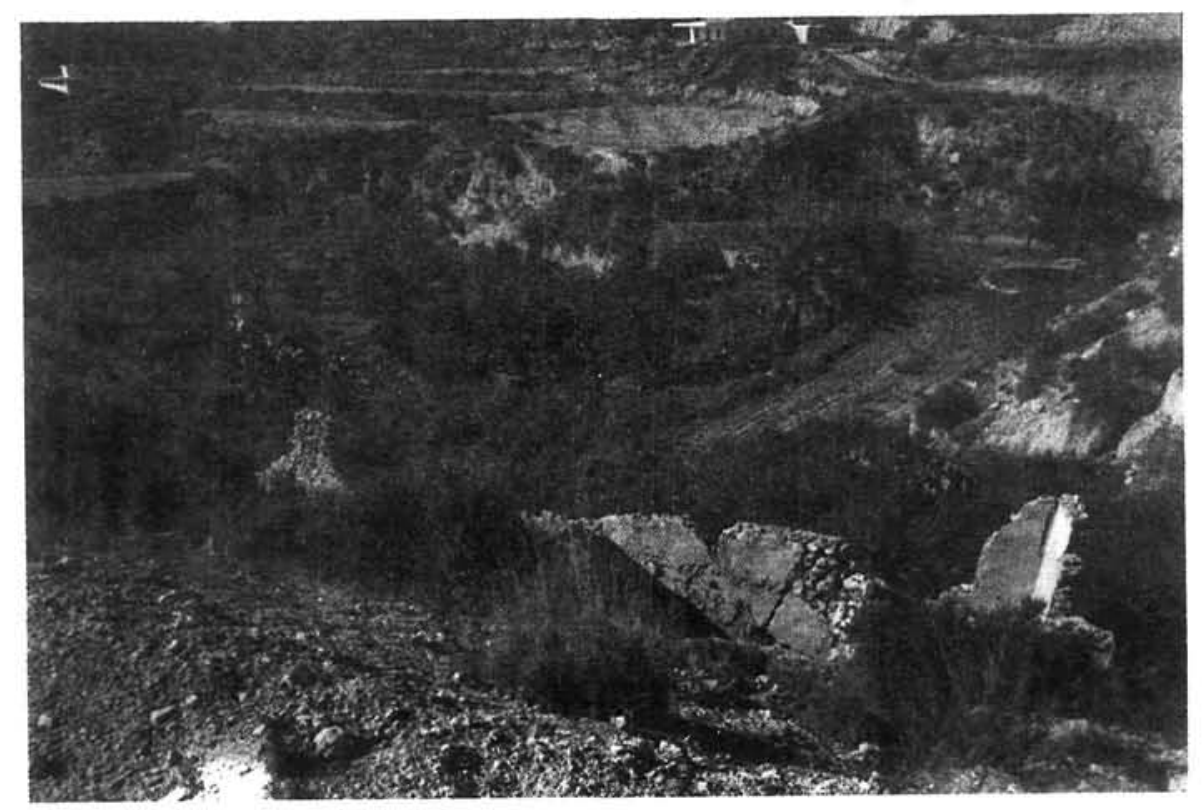

FIG. 2.-El despoblado de la Finca «Las Parretas» (Crevillente). 


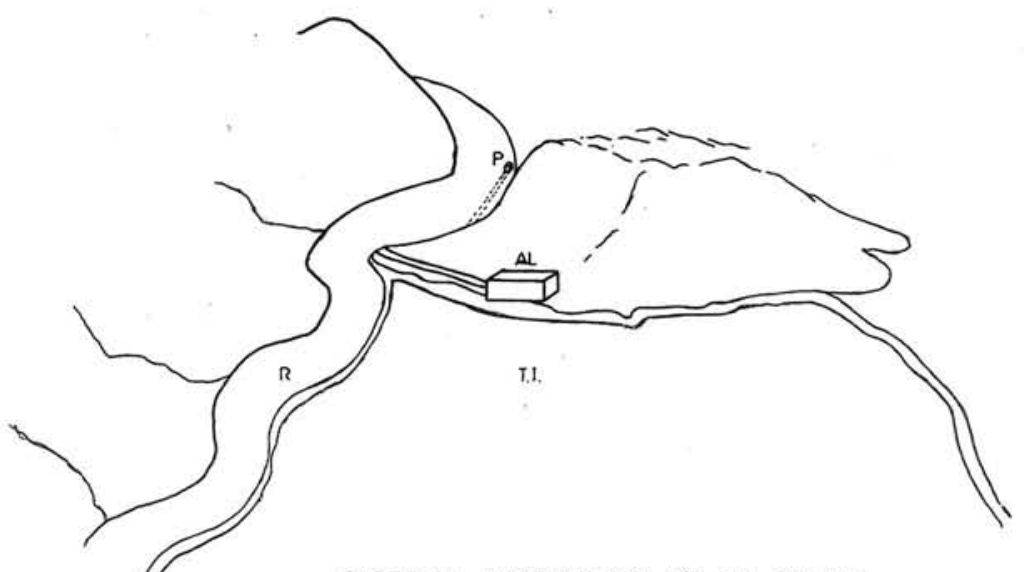

SISTEMA HIDRAULICO DE LA PALAYA
P Pozo
AL. Alberca
R Rambla
II Terrazas irrigadas

FIG. 3.-Sistema hidráulico de la Finca "La Palaya» (Crevillente)

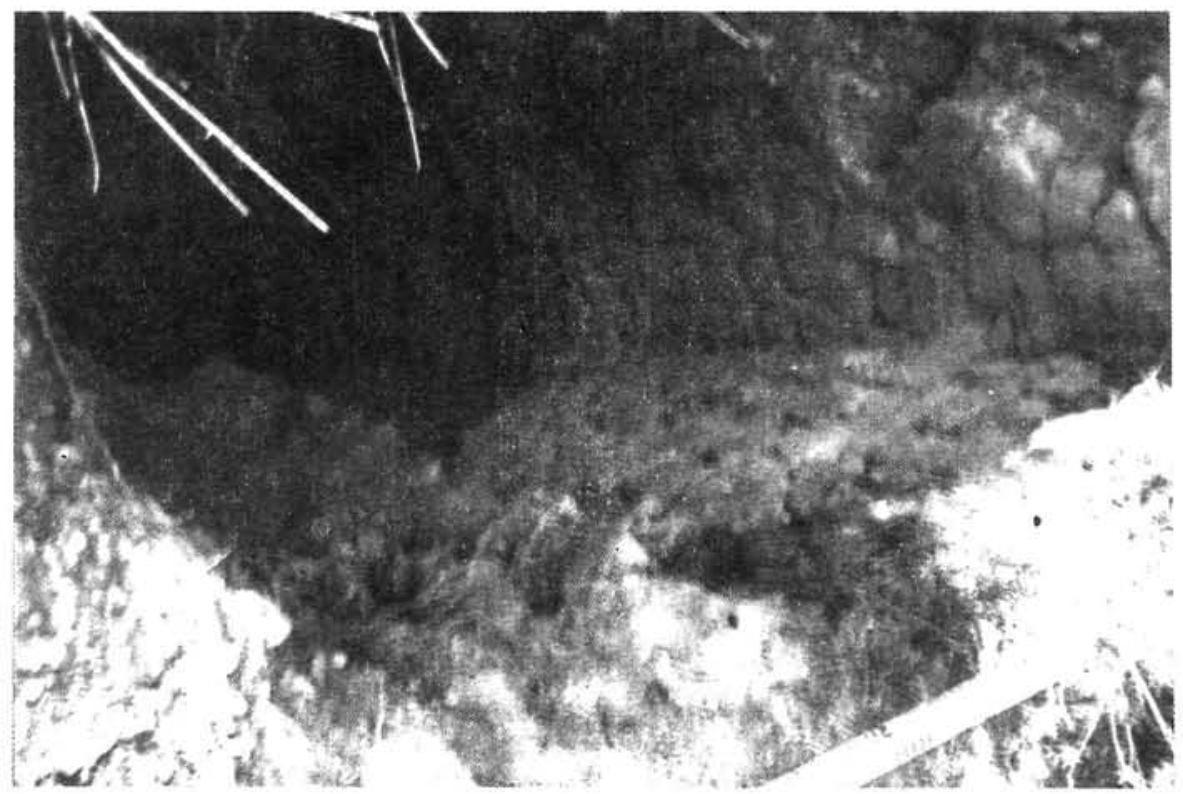

FIG. 4.-Pozo artesiano. Finca «La Molineta» (Crevillente). 


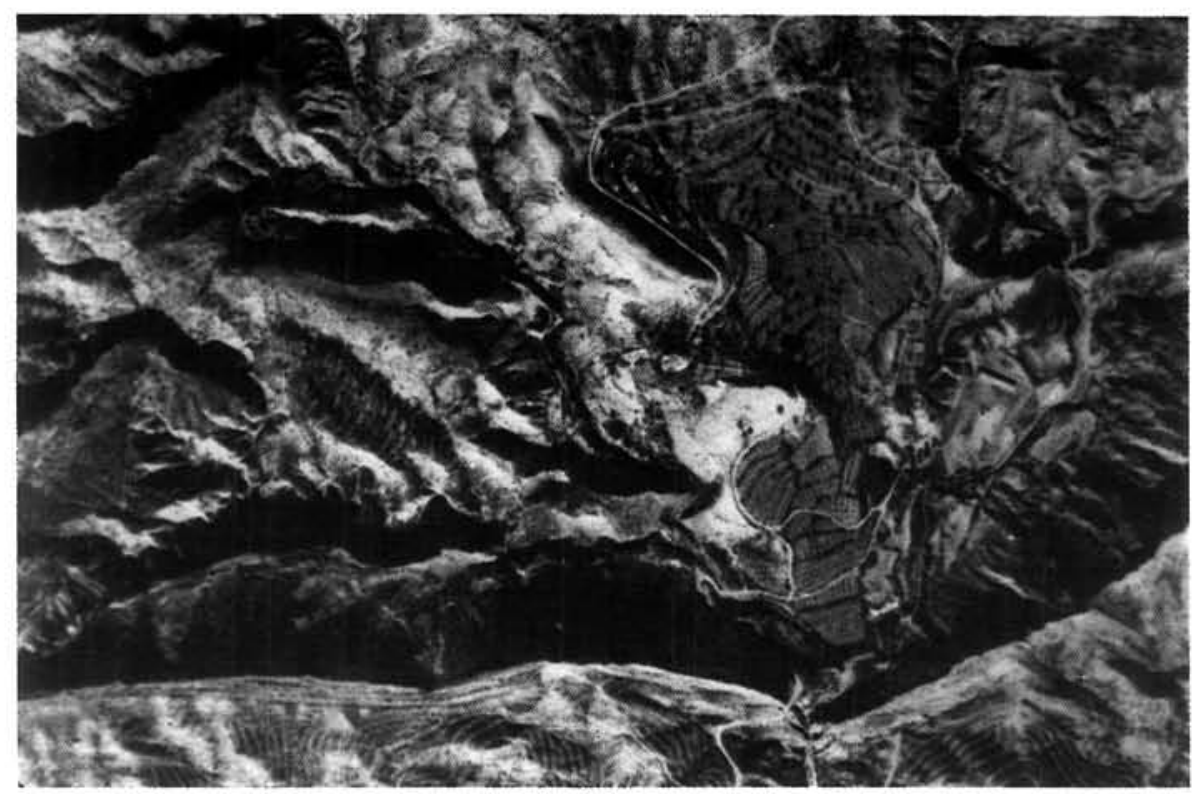

FIG. 5.-El «Oasis» de La Algüeda. Vista aérea de 1976.

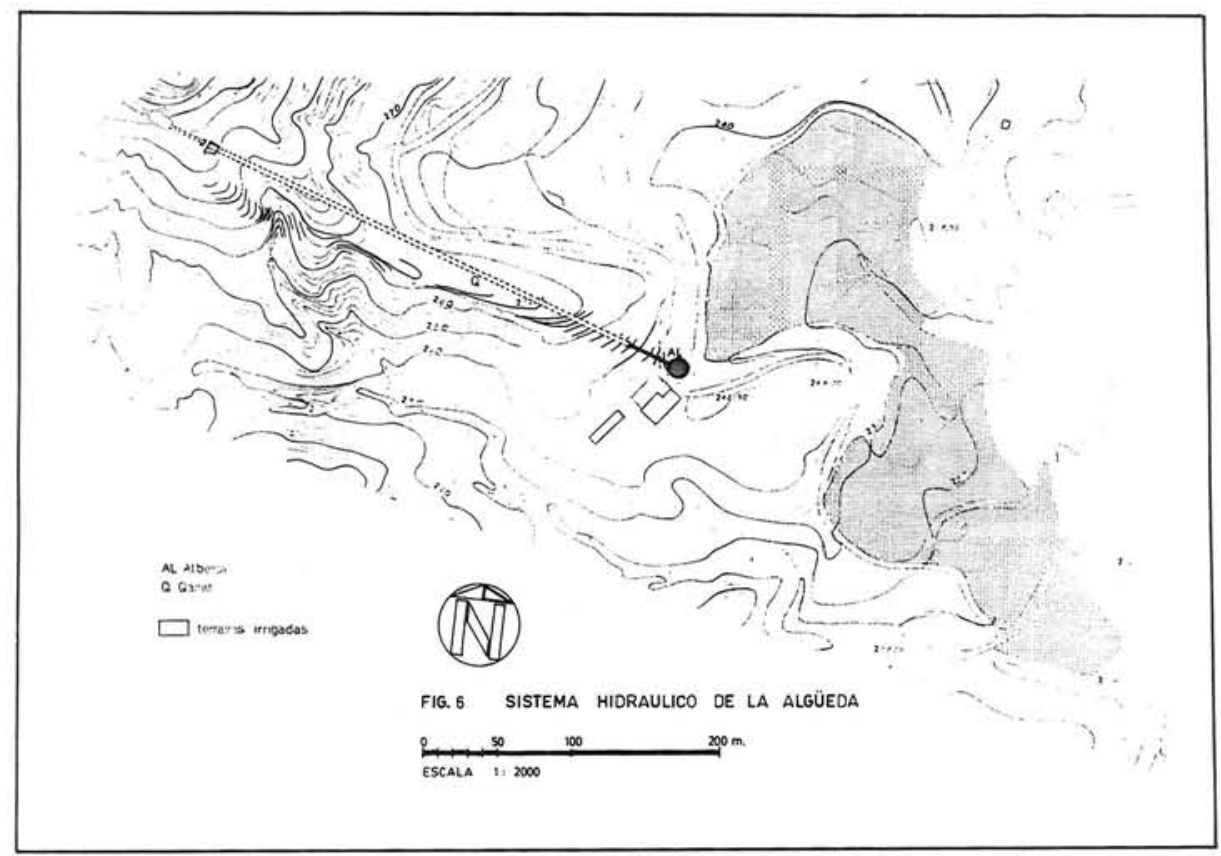

FIG. 6. - Sistema hidráulico de «La Algüeda» (Albatera). 


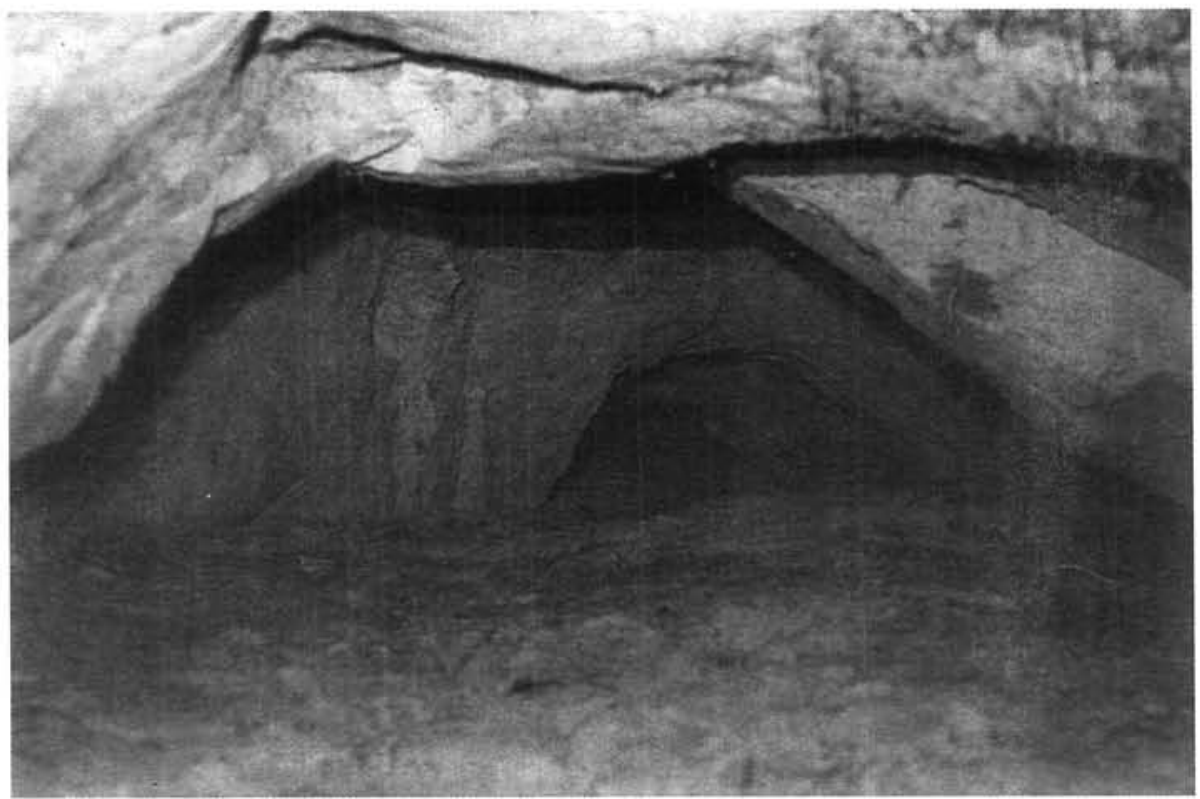

FIG. 7.- Tramo inicial de galeria de drenaje excavado en la roca.

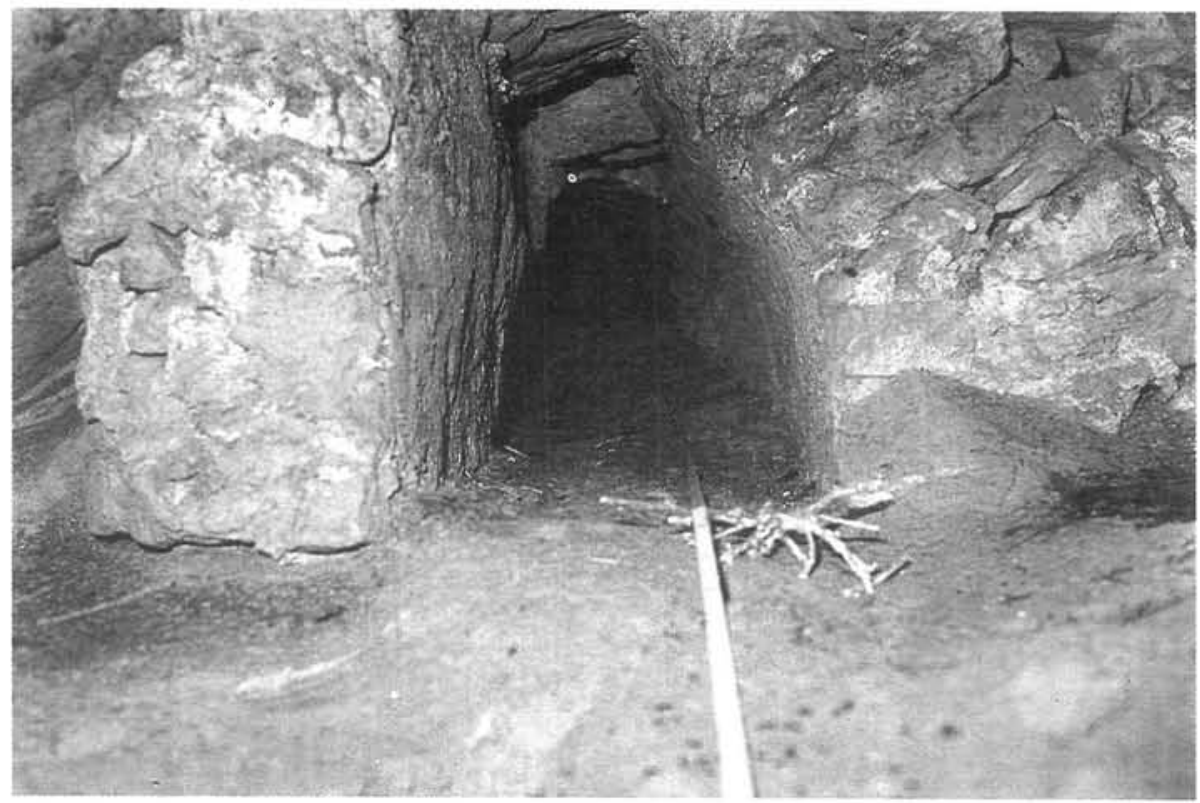

FIG. 8.-Comienzo del tramo intermedio de galería, configurado a partir del refuerzo de las paredes de la mina. 
FIG. 9.-Otro aspecto de la galeria en ser tramo intermedio muy anegado
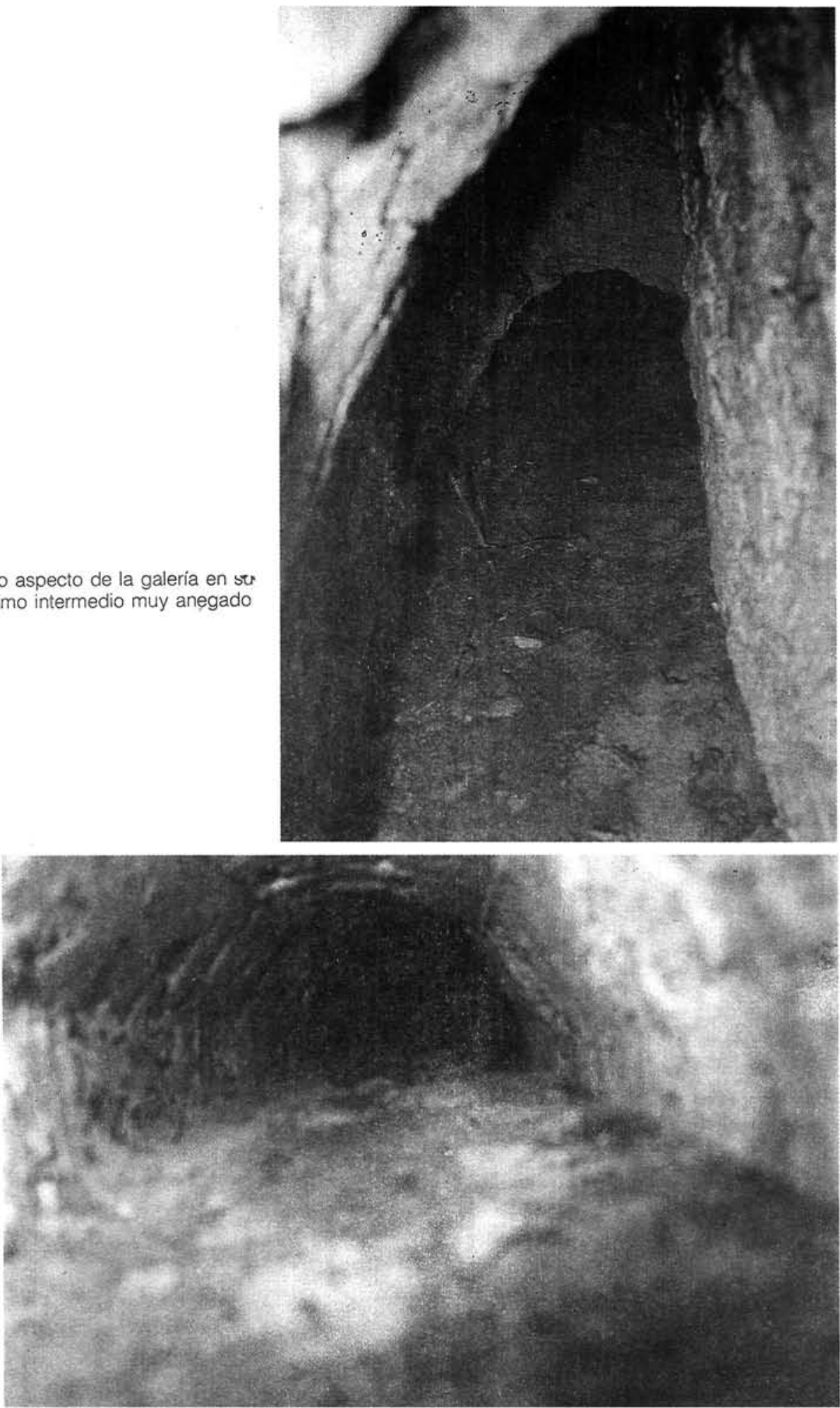

FIG. 10.- Un nuevo detalle donde se puede ver la impronta de la cimbra de madera que se utilizó para construir la cubierta. 


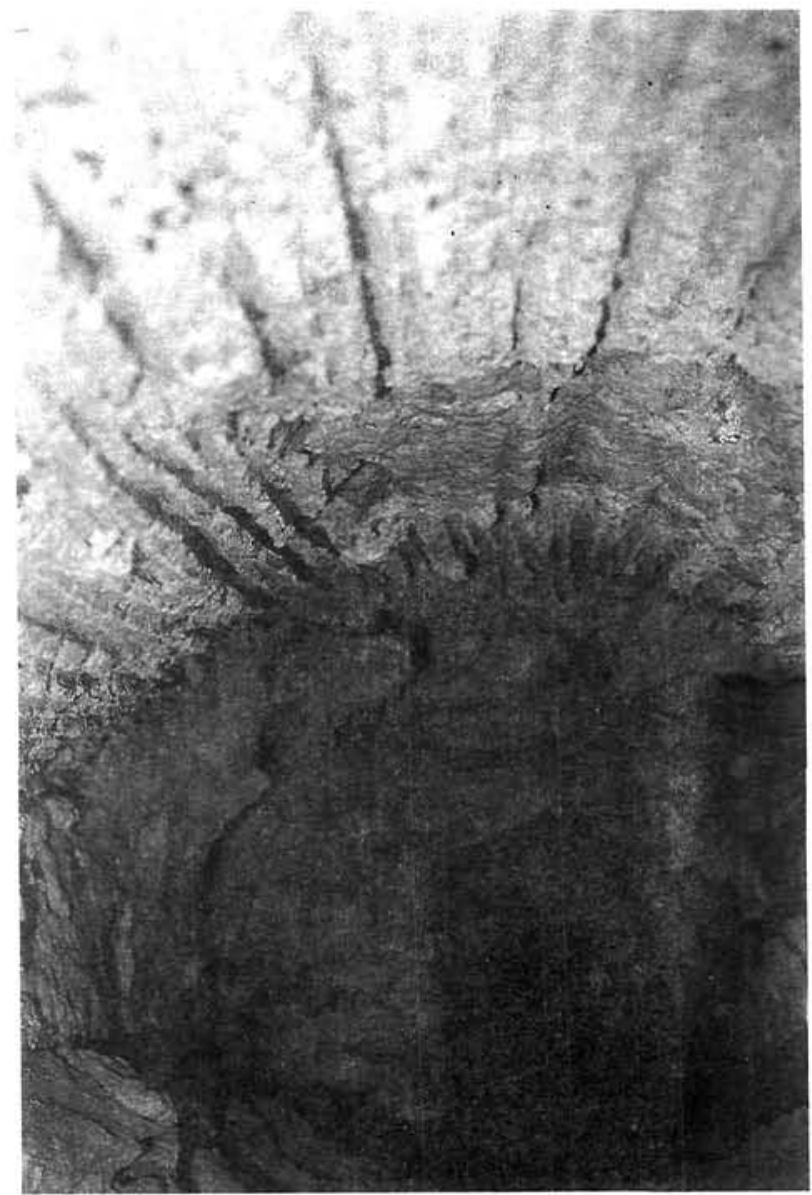

SISTEMAS DE CAPTACIÓN Y DISTRIBUCIÓN... I Gea

FIG. 11.-- Comienzo de la galeria de drenaje en su trayecto más amplio. Se puede ver el entronque con el tramo de galería intermedio y la nueva forma de la cubierta realizada a partir de una cimbra de cañas.

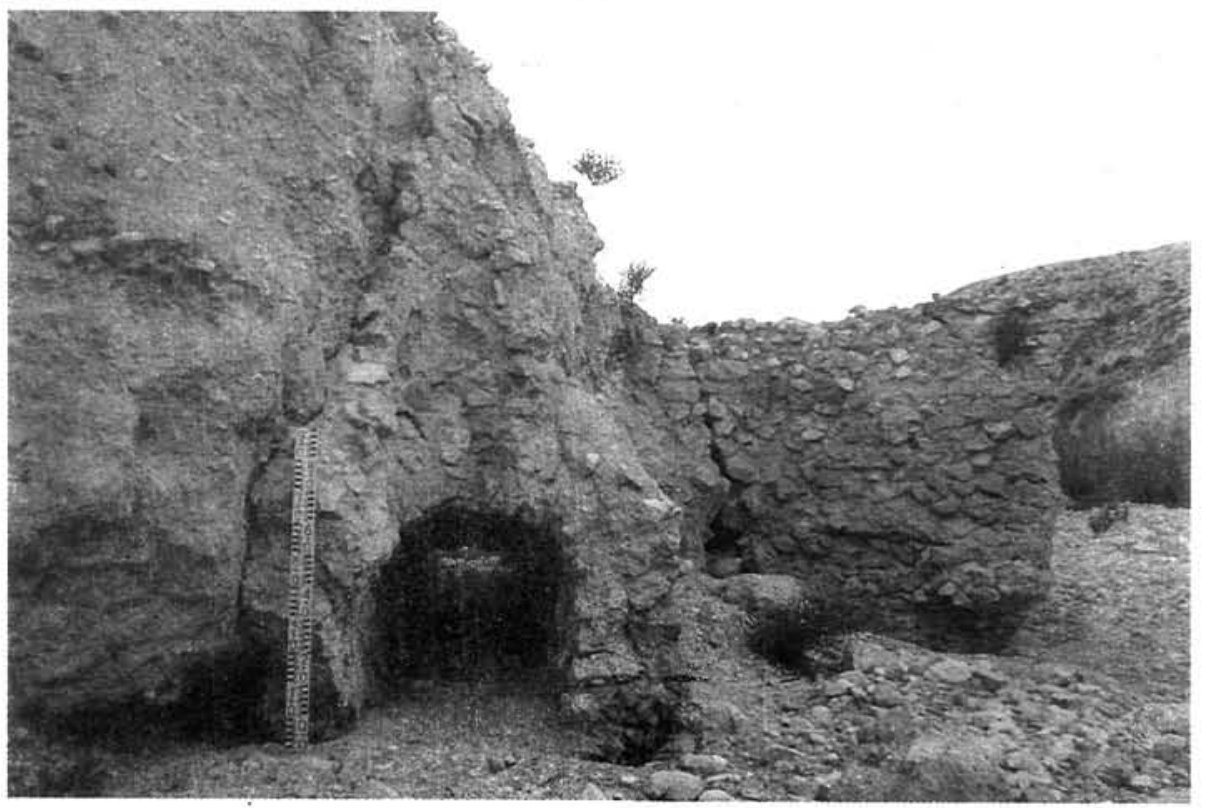

FIG. 12.-Corte de la galería producido por el torrente. 
FIG. 13.-Otro aspecto

'en el que se puede ver el reforzamiento de la cubierta.
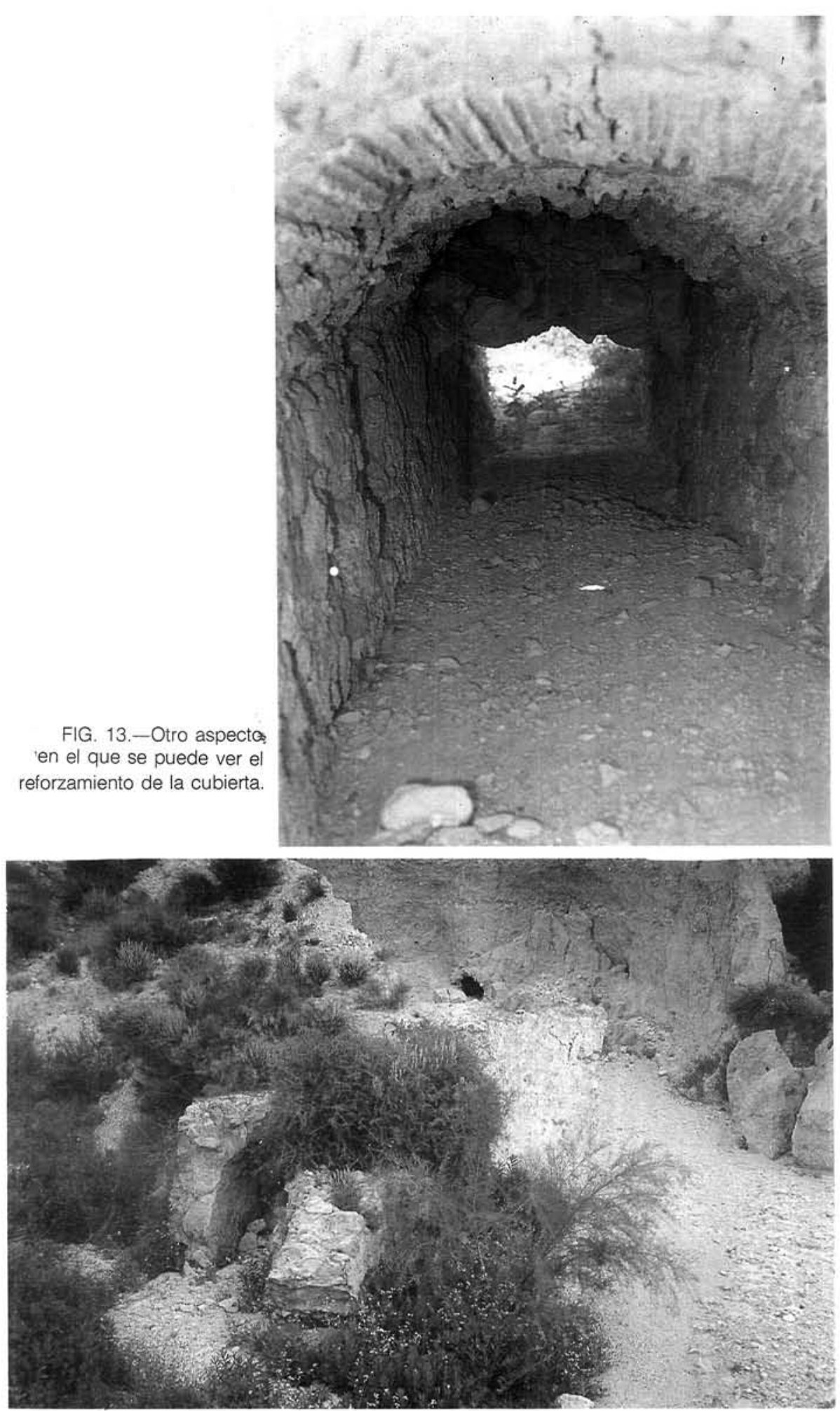

FIG. 14.- - La galeria de drenaje atravesando el lecho del torrente actual, en primer término se puede observar el reforzamiento de las paredes. 
SISTEMAS DE CAPTACIÓN Y DISTRIBUCIÓN... / Gea

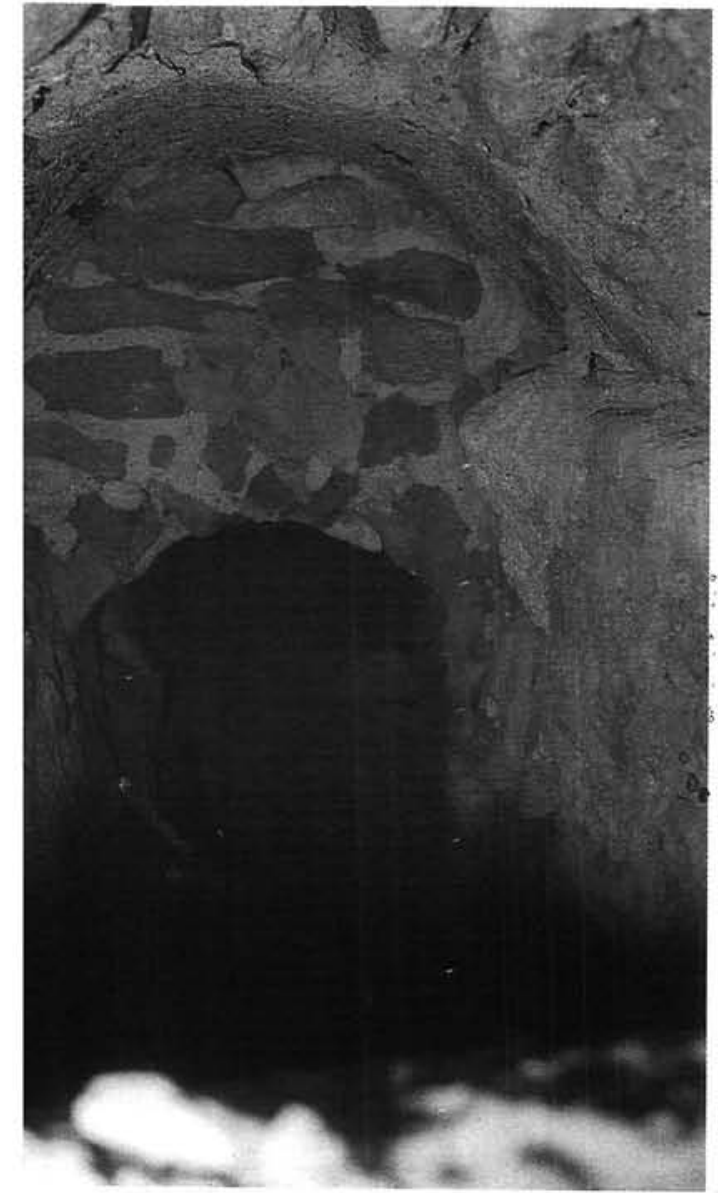

FIG. 15.-Aspecto de la galería reconstruida con mampostería recogida con yeso.

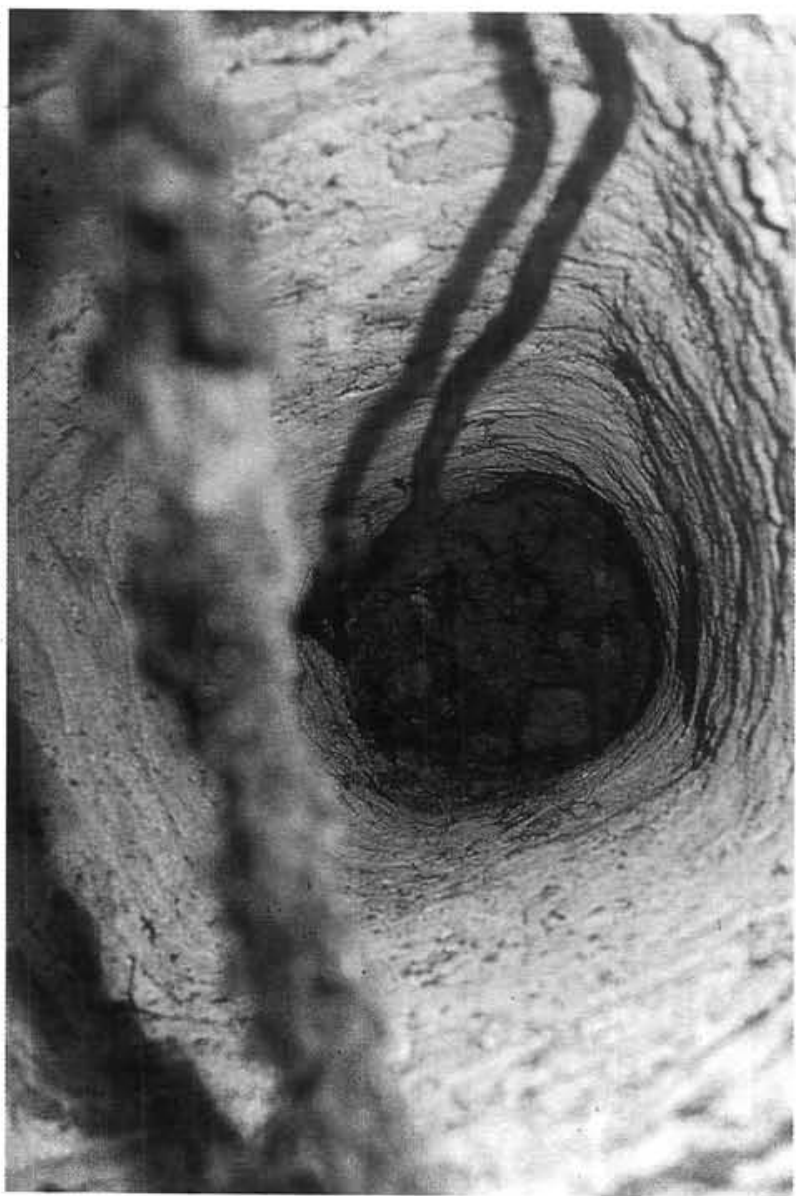

FIG. 16.-Pozo de ventilación de sección circular. 


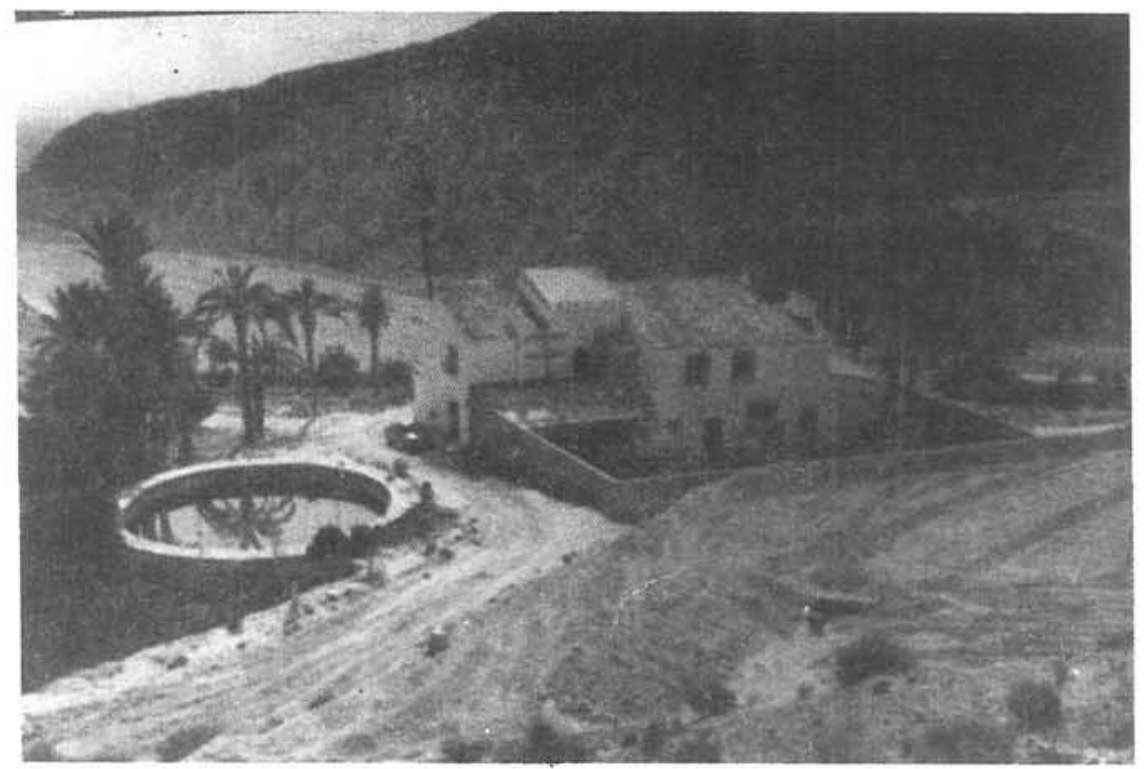

FIG. 17.-Alberca reguladora de sección circular.

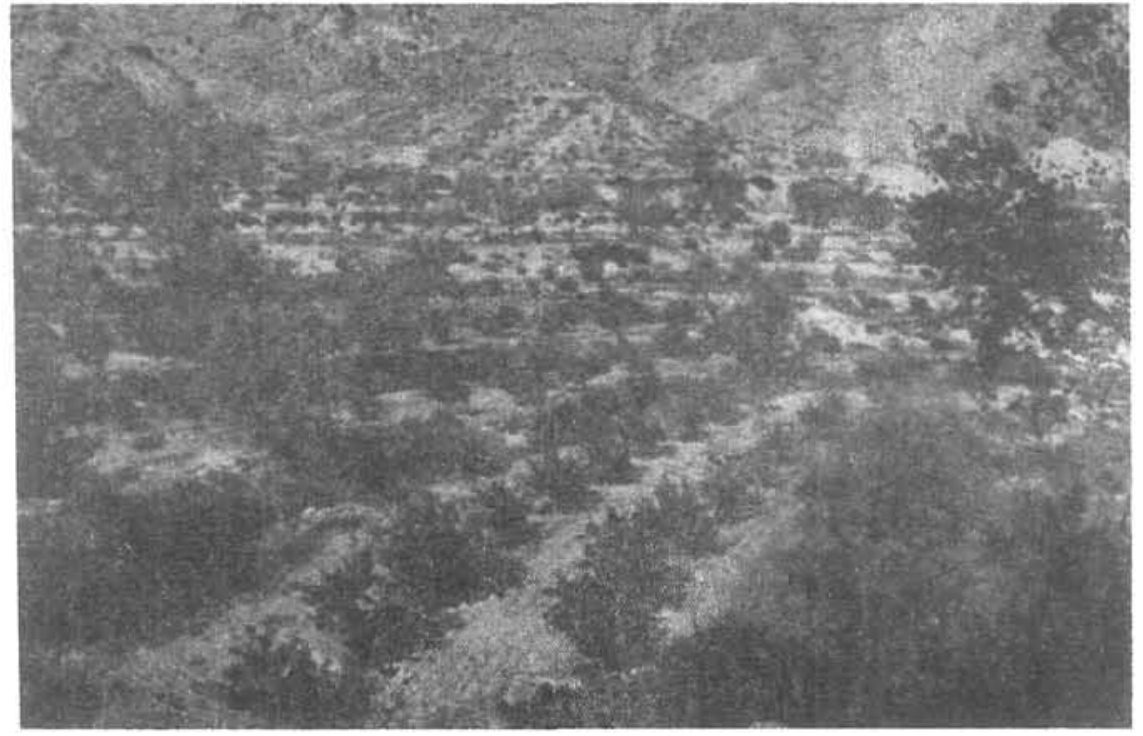

FIG. 18.-Detalle de la disposición del espacio irrigado. 


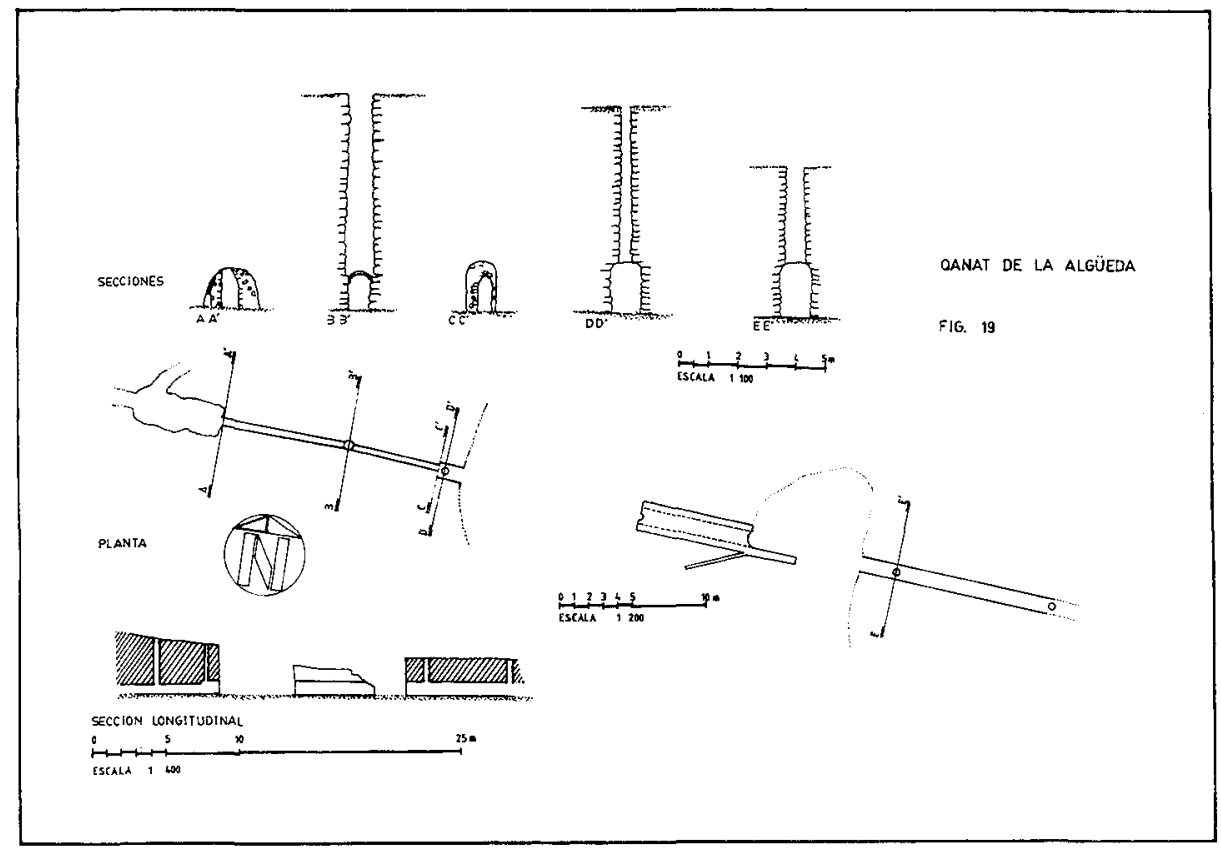

FIG. 19.-Qanat de La Algüeda.

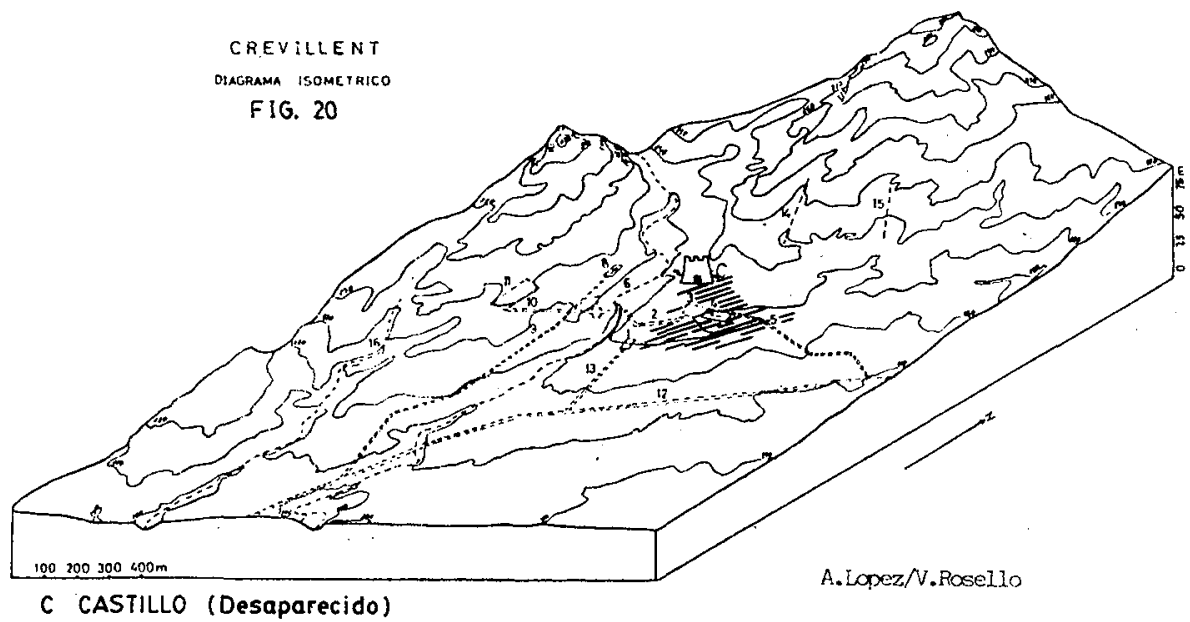

EA EMPLAZAMIENTO MEDIEVAL

Crevilleut (Bajo Visrelopó).-Bepresentación en relieve del emplazanicnto. 1. Mercado de abastus; 2, Calle Generalisium; 3. Plaza de los Martires; 4, Iglesia parroquial de Belén; 5, Cnlle Safrado Corazón: 6, la Rambla; 7, Plaxa Chapi: 8, Iglesia de la Santisima Trinidad; 9, Colle Santisima Trinidad; 10, Colle San Sebastián; 11, Pasco del Calvario; 12, Carroiera Alicante-Mureia; 13, Calle Virgen del Pilar; 14, Calle Angel; 15, Calle Virgen de la Salud; 16, Rambla do Ponent.

FIG. 20.-Croquización panorámica de la villa medieval de Crevillente. 


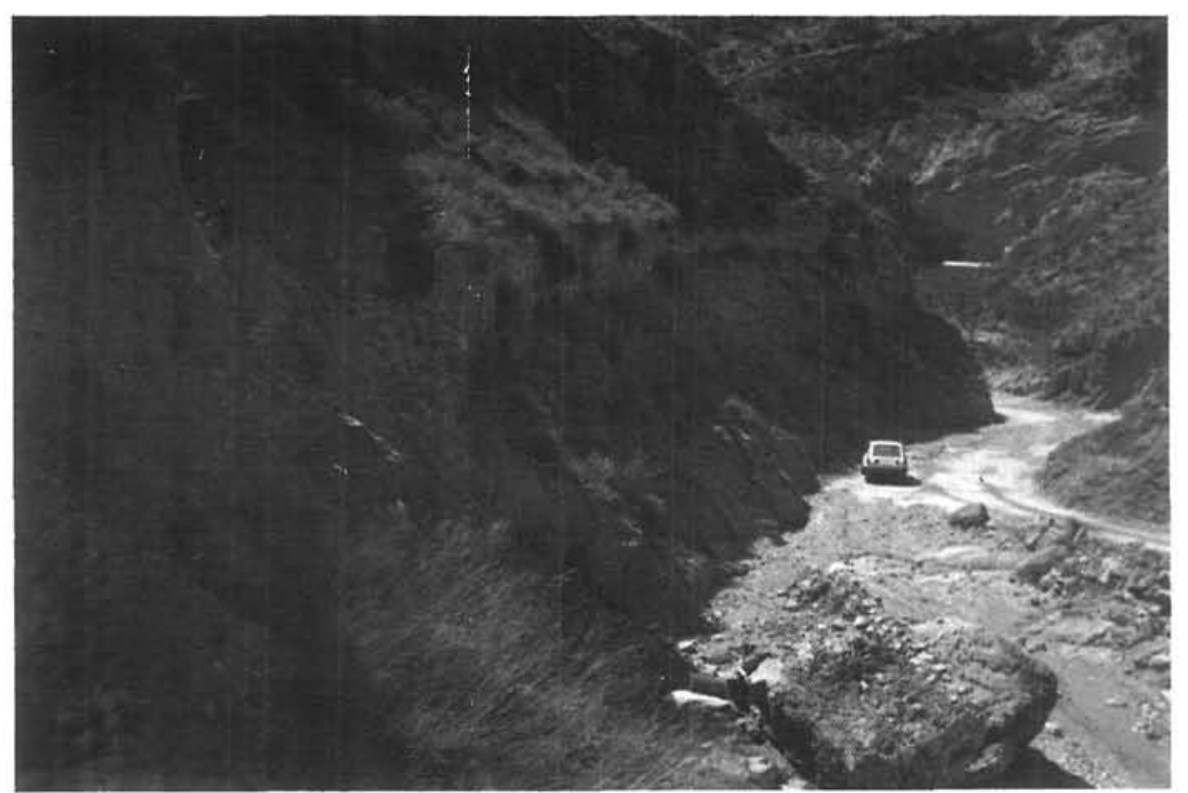

FIG. 21.-La «Font Antiga» de Crevillente bordeando en su tramo medio el lecho de la rambla. En el fondo bloque desgajado.

Estando en imprenta este artículo, llegó a nosotros el artículo publicado por M. Barceló, M. a A. Carbonero, R. Martí, G. Roselló-Bordoy: «La Font Antigua». En este estudio se establece una nueva lectura arqueológica de los restos medievales de la «Font Antigua» de Crevillente, identificándose captaciones distintas que dan lugar a galerías de drenaje también distintas, en cuyo caso habría que hablar mejor de «sistemas de qanats".

*Mi agradecimiento a Miguel Joye y Gerarda de Jayer por su amable colaboración y por haber conservado el «Oasiss de La Algüeda. También agradecemos a José Mora, Eduardo de Gea, Pascual Mora y Joaquín Garcia, su ayuda; sin la cual no hubiese podido realizar este trabajo. 